\title{
Sclerosing Mesenteritis Mimicking IgG4-related Disease
}

\author{
Masahide Fukuda ${ }^{1,2}$, Toru Miyake ${ }^{3}$, Akiko Matsubara ${ }^{1}$, Nobuyasu Ikai ${ }^{1}$, Eri Tanaka ${ }^{1}$, \\ Tomo Namura ${ }^{1}$, Yasuhiro Wada ${ }^{1,2}$, Mai Noujima ${ }^{1}$, Suzuko Moritani ${ }^{1}$, Kazunari Murakami ${ }^{2}$, \\ Akira Andoh $^{4}$, Masaji Tani ${ }^{3}$ and Ryoji Kushima ${ }^{1}$
}

\begin{abstract}
:
A 72-year-old man was followed as an outpatient at our hospital for 6 years after surgery for small cell carcinoma of left adrenal gland origin. Follow-up abdominal computed tomography showed a 6-cm mass in the left lower mesentery. The patient underwent open laparotomy. The histological diagnosis was sclerosing mesenteritis. The previous specimens of the left adrenal mass were then re-examined with a microscope, and panniculitis was found around the small cell carcinoma. Both lesions were histologically similar to IgG4related disease (RD), but they did not completely meet the diagnostic criteria of IgG4-RD clinically or histologically.
\end{abstract}

Key words: sclerosing mesenteritis, panniculitis, IgG4-related disease

(Intern Med 59: 513-518, 2020)

(DOI: 10.2169/internalmedicine.3221-19)

\section{Introduction}

Sclerosing mesenteritis (SM) is a nonspecific inflammatory disease of unknown etiology that occurs locally in mesenteric adipose tissue (1). Nonspecific inflammation in the mesentery was first described as "retractile mesenteritis" by Sulla in 1924 (2). Later, another report showed panniculitis of the mesentery characterized as inflammation in adipose tissue (3). These are now considered to be the same as SM.

Although SM is a benign condition, computed tomography (CT) shows an inhomogeneous, hyperattenuated, fatty mass, which makes it difficult to distinguish SM from a malignant tumor or lymphoma (4). Histopathologically, SM is characterized by the small bowel mesentery showing some degree of fibrosis, chronic inflammation with lymphocyte infiltration, and fat necrosis (5). In addition, some cases of SM show histologically characteristic findings of IgG4related disease (RD), such as an increased number of IgG4positive plasma cells, storiform fibrosis, and obliterative phlebitis. Therefore, these entities have been called "IgG4related mesenteritis" or "mimic of IgG4-RD" (6-18). While patients with IgG4-RD often have lesions in several organs, either synchronously or metachronously, there has been only one case report of IgG4-related SM with multi-organ IgG4RD involvement (10).

We herein report a case of SM with metachronous panniculitis histologically mimicking of IgG4-RD.

\section{Case Report}

A 72-year-old man with a history of surgery for small cell carcinoma of left adrenal gland origin at 66 years of age was followed as an outpatient at our hospital for 6 years, and abdominal CT was performed once a year to check for tumor recurrence. Abdominal CT revealed a high-density area appearing in the peritoneal cavity near the area of the original tumor. The lesion gradually grew each year, and he was aware of discomfort in the left lower abdomen. He was admitted for a clinical examination and treatment at this

\footnotetext{
${ }^{1}$ Division of Diagnostic Pathology, Department of Clinical Laboratory Medicine, Shiga University of Medical Science Hospital, Japan, ${ }^{2}$ Department of Gastroenterology, Oita University, Faculty of Medicine, Japan, ${ }^{3}$ Department of Surgery, Shiga University of Medical Science, Japan and ${ }^{4}$ Division of Gastrointestinal Endoscopy, Shiga University of Medical Science Hospital, Japan

Received: April 19, 2019; Accepted: September 13, 2019; Advance Publication by J-STAGE: November 8, 2019

Correspondence to Dr. Ryoji Kushima, kushima@belle.shiga-med.ac.jp
} 

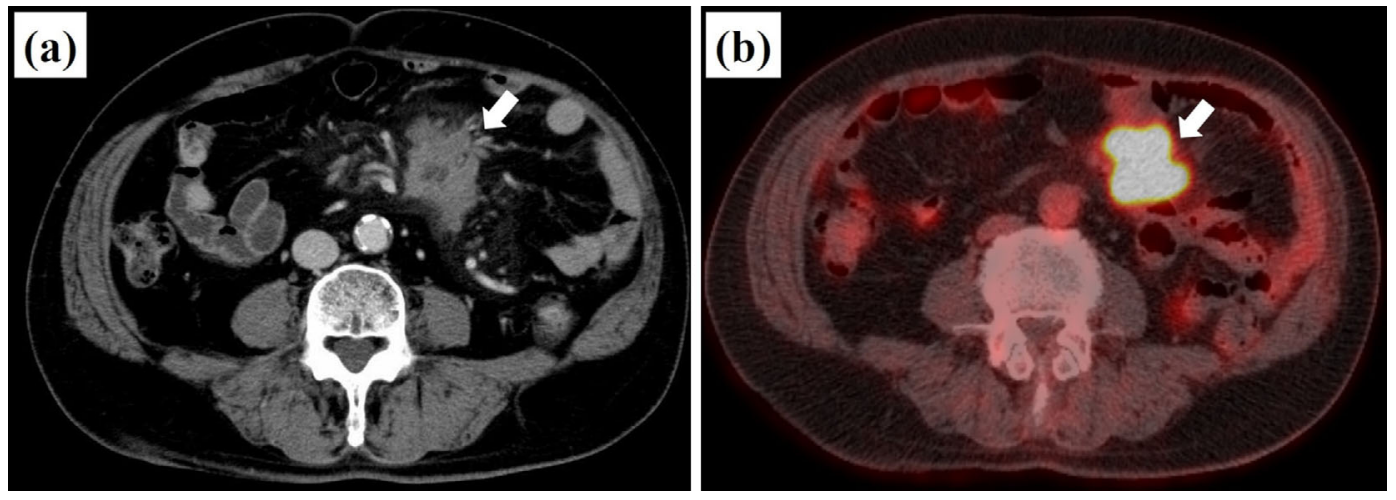

Figure 1. CT and PET-CT of abdomen at 72 years of age. (a) Contrast-enhanced CT shows a 6-cm lobulated mass with contrast effect in the left lower mesentery. (b) PET-CT shows the accumulation of fluorodeoxyglucose in the mesentery.
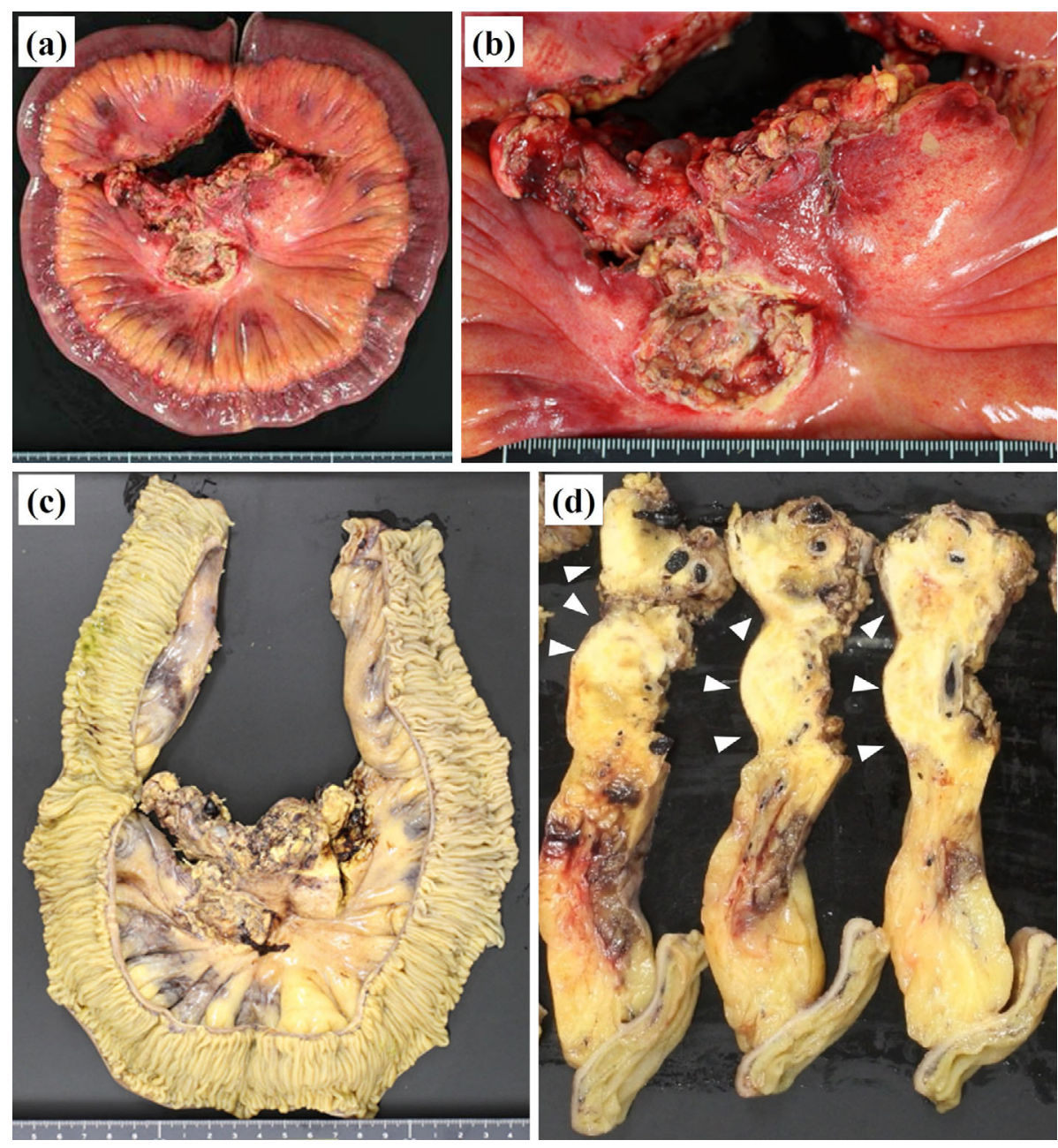

Figure 2. Macroscopic image of a partially resected specimen of the small intestine and mesentery at 72 years of age. (a) The surgically removed mesentery and small intestine are shown. (b) A 55×35$\mathrm{mm}^{2}$ large mass is located at the root of the mesentery. (c) The resected small bowel segment is $40 \mathrm{~cm}$ long, and no inflammation or hemorrhaging can be seen in the lumen. (d) The sagittal section shows white mass lesions with an unclear border with adipose tissue of the mesentery (arrowhead).

time.

Blood tests showed a mild elevation of C-reactive protein (CRP) to $0.44 \mathrm{mg} / \mathrm{dL}$ (normal: $<0.30 \mathrm{mg} / \mathrm{dL}$ ). Because of diabetes, his HbA1c level was increased to $7.2 \%$ (normal:
$<6.2 \%$ ). A high level of soluble IL-2 receptor (sIL2-R), 619 $\mathrm{U} / \mathrm{mL}$, was observed (normal: $<483.0 \mathrm{U} / \mathrm{mL}$ ). There was no increase in the levels of the tumor markers CEA, CA 19-9, NSE, or ProGRP. The serum IgG4 and IgG levels were 

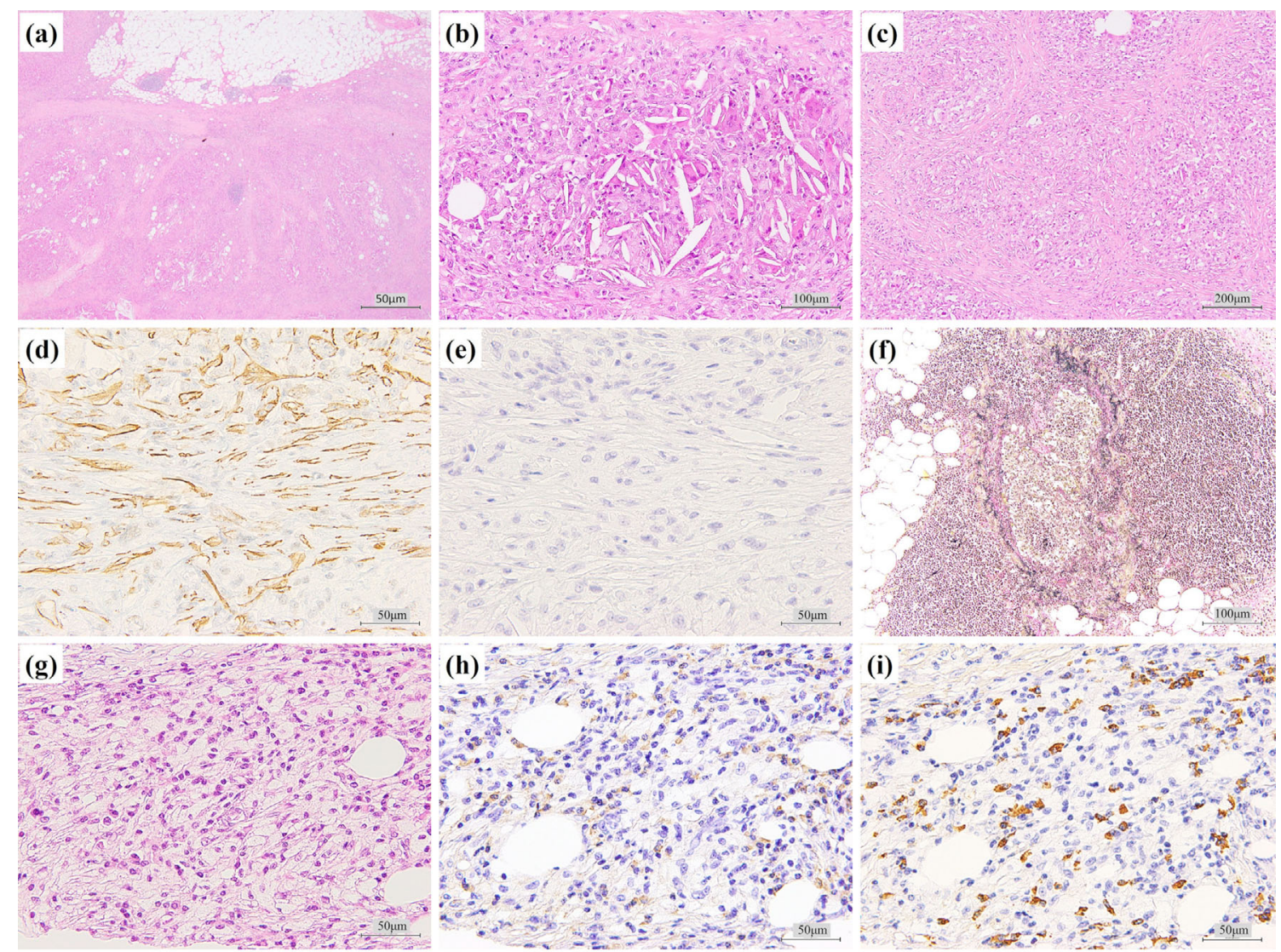

(j)

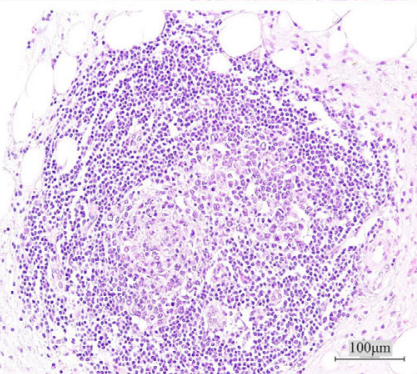

(k)

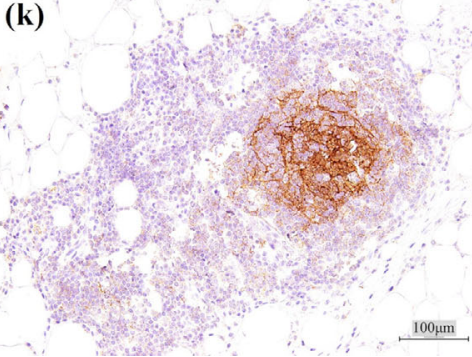

(I)

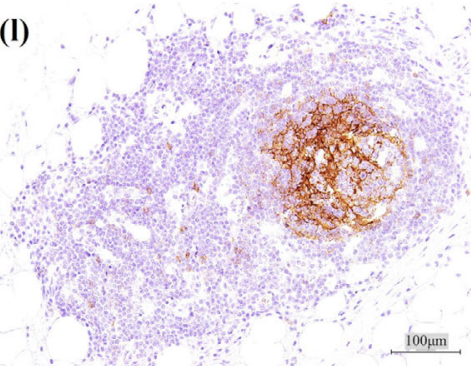

Figure 3. Histological findings of a partially resected specimen of the small intestine and mesentery at 72 years of age. (a) Findings of inflammation, fibrosis, and bleeding are observed in the adipose tissue. (b) Multinucleated giant cells and foamy histiocytes are admixed with a cholesterol cleft and chronic inflammatory cells. (c) Spindle cells are located in an irregular fashion. (d) The spindle cells are positive on immunohistochemical staining for $\alpha$-SMA. (e) The spindle cells are negative on immunohistochemical staining for ALK. (f) Elastica van Gieson staining shows that the vessel is completely obliterated by the dense inflammation. (g) Numerous lymphocytes, including plasma cells are mixed in with foamy cells. Immunohistochemical staining for plasma cells with IgG (h) and IgG4 (i) shows an IgG4-/IgG-positive cell ratio of approximately 87\%. (j) Lymphoid follicles consisting of lymphocytes without atypia are seen. (k, l) Immunohistochemical staining with CD21 (k) and CD23 (l) is positive only in the follicle center.

measured from preoperative preserved blood samples after the surgery, and $\mathrm{IgG} 4$ was within the normal range, 50.8 $\mathrm{mg} / \mathrm{dL}$ (reference range, 4.8 to $105.0 \mathrm{mg} / \mathrm{dL}$ ), while $\mathrm{IgG}$ was mildly increased to $2,056 \mathrm{mg} / \mathrm{dL}$ (reference range, 870 to $1,700 \mathrm{mg} / \mathrm{dL}$ ).

$\mathrm{CT}$ of the abdomen and pelvis showed a $6-\mathrm{cm}$ mesenteric mass in the left lower abdominal cavity. CT with intravenous contrast showed the tumor with a mild contrast effect (Fig. 1a). Positron emission tomography-CT showed a significant fluorodeoxyglucose uptake $\left(\mathrm{SUV}_{\max }\right.$ : 6.5) (Fig. 1b).
Clinically, SM or recurrence of small cell carcinoma was considered. Laparoscopic surgery was first performed, but the intraoperative rapid diagnosis revealed only necrotic tissue. Because it was difficult to diagnose the mass as a notmalignant tumor in small pieces, the mass was resected along with the mesentery and part of the small intestine via open laparotomy.

On a macroscopic examination when the patient was 72 years of age, the resected small bowel segment was $40 \mathrm{~cm}$ long (Fig. 2a), and the stiff mass at the root of the mesen- 

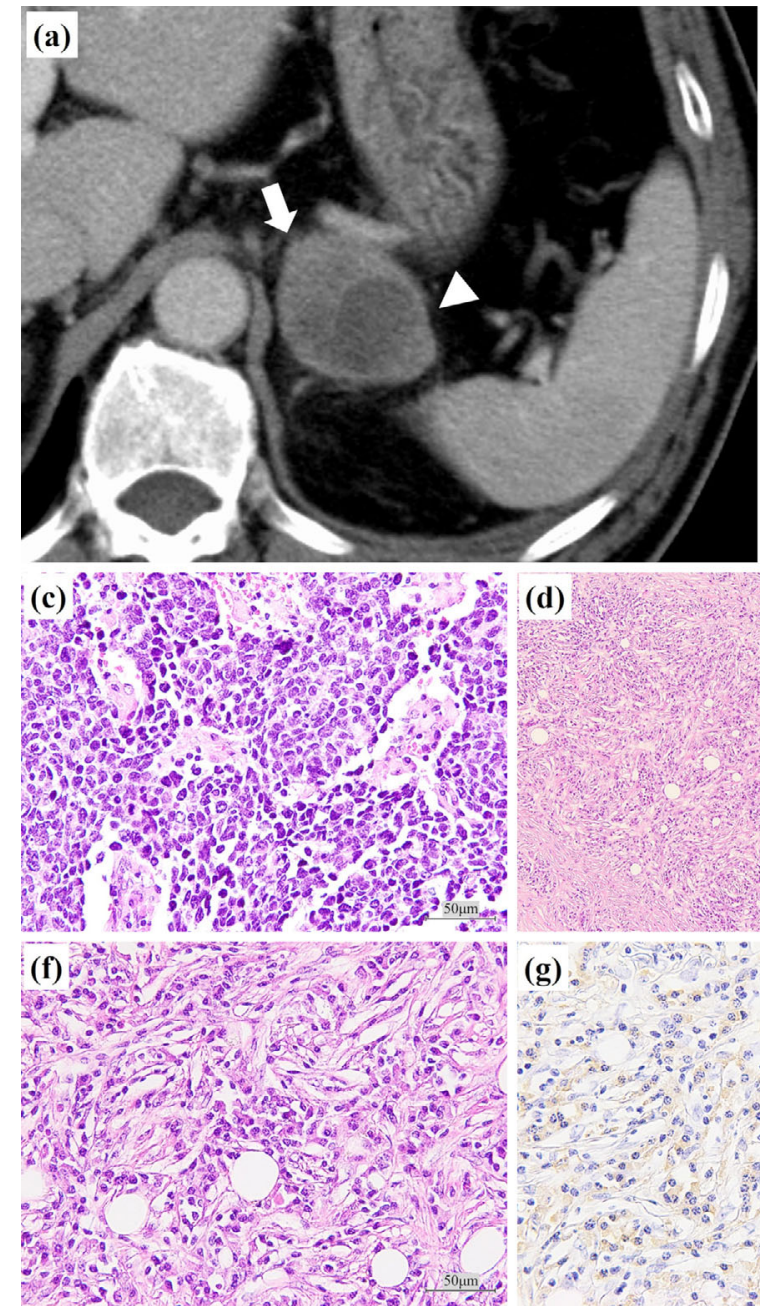

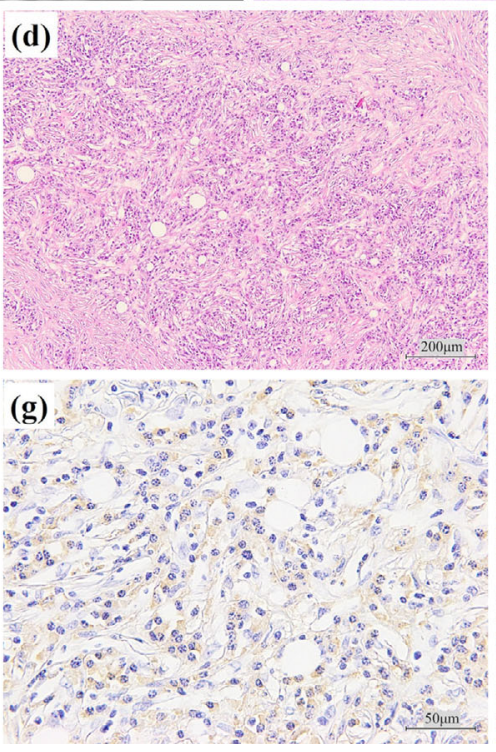

(d)
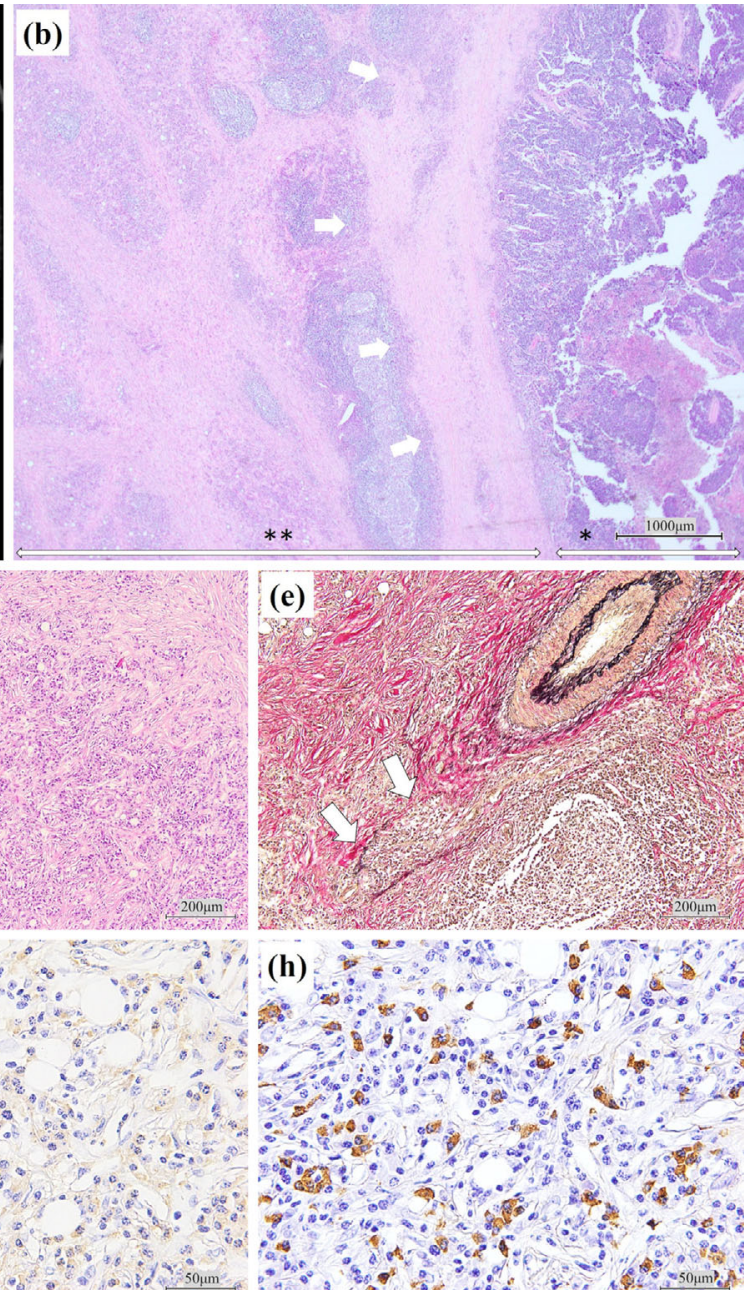

Figure 4. CT of the abdomen and histopathological findings of the left adrenal mass and surrounding sclerosing lesion at 66 years of age. (a) Contrast-enhanced CT shows a circular, low-density area (arrow) in an oval iso-density area (arrowhead). (b) The low-magnification view of the specimen of the resected left adrenal mass shows a solid tumor (*) surrounded by sclerosing fibrosis (arrow) (**). (c) The high-magnification view of the tumor shows that the tumor consists of small atypical cells with a high nucleus to cytoplasm ratio with hyperchromatic nucleoli. (d-h) High-magnification view of the sclerosing fibrosis area. (d) The spindle cells are proliferated in an irregular fashion. (e) Elastica van Gieson staining shows the vessel with obstructive phlebitis. (f) Many plasma cells are mixed in with foamy cells. (g, h) Immunohistochemical staining for plasma cells with IgG (g) and IgG4 (h) shows an IgG4-/IgG-positive cell ratio of approximately $60 \%$.

tery was $5.5 \mathrm{~cm} \times 3.5 \mathrm{~cm}$ in size (Fig. 2b). There were no neoplastic lesions or ischemic changes in the lumen of the small intestine (Fig. 2c). Multiple cross sections of the mass and mesentery showed a solid fibrotic mass with an unclear border and surrounding adipose tissue (Fig. 2d). On a histopathological examination, the mass was mainly composed of fat necrosis and a sclerosing fibrotic lesion with lymphoplasmacytic infiltration and lymphoid follicles (Fig. 3a). Some giant cells and cholesterol clefts were observed in the fat necrosis (Fig. 3b). Sclerosing fibrosis was arranged in an irregular manner (Fig. 3c). Spindle cells in the area of fibrosis were positive for $\alpha$-SMA (Fig. 3d) and negative for ALK (Fig. 3e). Elastica van Gieson (EVG) staining showed the findings of obliterative phlebitis (Fig. 3f). The area of fat necrosis showed infiltration by lymphocytes and plasma cells (Fig. 3g). In the sclerosing fibrotic lesion, increased number of plasma cells were observed (Fig. $3 \mathrm{~g}$ ). IgG and IgG4 immunohistochemical staining showed focally increased numbers of IgG- and IgG4-positive plasma cells (Fig. 3h and i, respectively). When 5 different high-power fields (hpfs) were counted, the average number of IgG4positive cells was 81 (range, 53-104), whereas the IgG4-/ IgG-positive cell ratio was $80.4 \%$ (range, 60.9-92.4\%). Lymphocytes without atypia that formed lymphoid follicles were observed (Fig. 3j), and immunohistochemical staining for CD21 (Fig. 3k) and CD23 (Fig. 31) was positive only in the follicle center. Given the above results, the histological diagnosis of the mass lesion was SM. However, there were insufficient typical findings to diagnose the lesion as IgG4related SM clinically or histologically. In the differential di- 
Table. Summary of Past Reports with IgG4-related SM or Mimicking of IgG4-related SM.

\begin{tabular}{|c|c|c|c|c|c|c|c|c|c|}
\hline \multirow[b]{2}{*}{$\begin{array}{c}\text { case } \\
\text { (Reference) }\end{array}$} & \multirow[b]{2}{*}{$\begin{array}{l}\text { Age } \\
(y)\end{array}$} & \multirow[b]{2}{*}{ Sex } & \multirow{2}{*}{$\begin{array}{c}\text { Serum } \\
\text { IgG4 } \\
(\mathrm{mg} / \mathrm{dL})\end{array}$} & \multirow[b]{2}{*}{ Sample } & \multicolumn{2}{|c|}{ Immunohistochemistry } & \multirow[b]{2}{*}{ Fibrosis } & \multirow[b]{2}{*}{$\begin{array}{l}\text { Obliterative } \\
\text { phlebitis }\end{array}$} & \multirow{2}{*}{$\begin{array}{c}\text { IgG4-related disease at } \\
\text { other sites }\end{array}$} \\
\hline & & & & & $\begin{array}{l}\mathrm{IgG} 4 \\
(/ \mathrm{hpf})\end{array}$ & $\begin{array}{c}\mathrm{IgG} 4 / \\
\operatorname{IgG}(\%)\end{array}$ & & & \\
\hline $2[1]$ & 52 & male & NA & resection & 13 & NA & yes & yes & none \\
\hline $3[1]$ & 63 & female & NA & biopsy & 16 & NA & yes & yes & none \\
\hline $4[1]$ & 65 & male & NA & biopsy & 16 & NA & yes & yes & none \\
\hline $5[1]$ & 74 & male & NA & biopsy & $>100$ & $>33$ & yes & no & none \\
\hline $6[1]$ & 46 & male & NA & resection & $>100$ & $>33$ & yes & yes & none \\
\hline $7[2]$ & 42 & male & 119 & resection & 60 & 40 & yes & NA & none \\
\hline $8[3]$ & 82 & female & 171 & resection & 130 & 75.9 & yes & yes & none \\
\hline $9[4]$ & 53 & male & 127 & resection & 74.8 & 64 & yes* & yes & none \\
\hline $10[5]$ & 64 & male & 81 & biopsy & 38 & 80 & yes* & yes & retroperitoneal fibrosis \\
\hline $11[6]$ & 76 & male & 63.5 & biopsy & 56 & 33 & yes* & yes & none \\
\hline $13[6]$ & 54 & male & 105 & resection & 85 & 35 & yes* & yes & none \\
\hline $14[7]$ & 70 & female & 213 & resection & NA & $>90$ & yes* & yes & none \\
\hline $15[8]$ & 54 & male & "normal" & biopsy & "rich" & NA & yes & yes & none \\
\hline 16 [9] & 62 & male & 179 & biopsy & NA & NA & NA & NA & none \\
\hline $17[10]$ & 56 & female & 134 & resection & "increase" & NA & yes & no & none \\
\hline $18[11]$ & 7 & female & 149 & biopsy & “predominant" & NA & yes & NA & none \\
\hline $19[12]$ & 56 & male & 416 & biopsy & "dense infiltration" & NA & yes* & NA & none \\
\hline $20[13]$ & 60 & male & 47 & resection & $>40$ & NA & yes* & yes & none \\
\hline Present case & 72 & male & 50.8 & resection & 81 & 80.4 & yes & yes & none \\
\hline
\end{tabular}

*Storiform fibrosis.

hpf: high-power field, NA: not available

agnosis, inflammatory myofibroblastic tumor and follicular dendritic sarcoma were considered, but they were excluded based on the results of immunohistochemistry (ALKnegative and both CD21- and CD23-negative, respectively).

Previous medical records and specimens were then reexamined considering the possibility that IgG4-RD may have existed metachronously in multiple organs. The contrast-enhanced CT image of the left adrenal small cell carcinoma at 66 years old showed a round, low-density area with a surrounding oval iso-density area (Fig. 4a). Histologically, the round area matched the location of the small cell carcinoma, and the surrounding oval area was sclerosing fibrosis (Fig. 4b, c). In the sclerosing fibrotic lesion, the findings of irregularly arranged fibrosis, obliterative phlebitis, and increased number of plasma cells were observed (Fig. 4d-f). IgG and IgG4 immunohistochemical staining showed focally increased numbers of IgG- and IgG4positive plasma cells (Fig. 4g, h). When 5 different hpfs were examined, the average number of IgG4-positive cells was 78.6 (range, 57-113), and the IgG4-/IgG-positive cell ratio was $48.4 \%$ (range, $36-60 \%$ ). The lesion was therefore diagnosed as panniculitis. However, there were insufficient typical findings to diagnose the lesion as retroperitoneal fibrosis clinically or histologically.

The patient has been free from recurrence for 20 months since the surgery for SM.

\section{Discussion}

The present case was diagnosed as SM, and panniculitis had emerged six years before the operation for SM. SM is a rare idiopathic disease characterized by chronic inflammation and fibrosis in the adipose tissue of the bowel mesentery. Recently, some case reports and case series have shown the relationship between SM and IgG4-RD (6-18). IgG4-RD has been newly recognized as a systemic disease and a protean condition that mimics many malignant, infectious, and inflammatory disorders (19).

The diagnosis of IgG4-RD relies on the combined presence of the characteristic histopathological appearance and increased numbers of IgG4-positive plasma cells. The critical histopathological features are a dense lymphoplasmacytic infiltrate, a storiform pattern of fibrosis, and obliterative phlebitis (20). A consensus has been reached concerning 2 diagnostic criteria for IgG4-RD: 1) serum IgG4 concentration $>135 \mathrm{mg} / \mathrm{dL}$, and 2) $>40 \%$ of IgG-positive plasma cells being IgG4-positive and $>10$ cells/hpf on a biopsy sample (21). According to the resected specimens of IgG4-RD, IgG4-positive plasma cells are usually present at numbers exceeding 50/hpf and typically exceeding 100/hpf (22).

Some case reports of IgG4-related SM or possible IgG4$\mathrm{RD}$, including the present case, are summarized in Table (6-18). These IgG4-related SM cases occurred predominantly in older men, as is observed with IgG4-RD (23). The 
mean age of 21 patients with IgG-related SM was 58.4 (range, 7-82) years, and the sex ratio was 2.5:1 (men: women). Furthermore, most SM cases have been histologically similar to IgG4-RD, since findings of increased numbers of IgG4-positive plasma cells, lymphoplasmacytic infiltrate, storiform fibrosis, and obliterative phlebitis are observed. However, as Avincsal et al. reported, conclusive cases with the four characteristic features (high serum IgG4 level, tissue IgG4 elevation, multi-organ involvement, and steroid responsiveness) have never been reported (11). Although the present patient had an SM lesion that was histologically similar to IgG4-RD, irregularly arranged fibrosis was not typical storiform pattern fibrosis and increased $\mathrm{IgG} 4$ positive cells were located focally. And clinically, the patient's serum IgG4 levels were within the normal range. Therefore, we were not able to diagnose the SM lesion as IgG4-RD.

It is known that many patients with IgG4-RD have lesions in several organs, either synchronously or metachronously (21). In the present case, panniculitis around the small adenocarcinoma in the left adrenal gland was found six years before the operation for SM. The panniculitis was histologically similar to retroperitoneal fibrosis because not only abundant IgG4-positive cells but also findings of irregularly arranged fibrosis and obliterative phlebitis were observed. However, IgG4-positive cells have also been observed in carcinoma-associated inflammatory response lesions (24). Furthermore, in the present case, the irregularly arranged fibrosis differed from the typical finding of a storiform pattern, as in IgG4-RD, and IgG4-positive cells were increased focally. Therefore, we were unable to diagnose the panniculitis as retroperitoneal fibrosis.

According to previous reports, only one case has shown multi-organ involvement. In that case, retroperitoneal fibrosis appeared five months after the operation for IgG4-related SM (10). Another two idiopathic SM cases with retroperitoneal fibrosis have also been reported $(25,26)$. These case reports suggest a potential association between SM and IgG4RD. Of note, in our present case, not only the SM lesion but also the metachronous panniculitis were histologically similar to IgG4-RD.

In conclusion, we encountered a case of SM mimicking IgG4-RD. A comprehensive examination, including a review of the patient's clinical and histological information, may be important for the accurate diagnosis of SM.

The authors state that they have no Conflict of Interest (COI).

\section{References}

1. Emory TS, Monihan JM, Carr NJ, Sobin LH. Sclerosing mesenteritis, mesenteric panniculitis and mesenteric lipodystrophy: a single entity? Am J Surg Pathol 21: 392-398, 1997.

2. Jura V. Sulla mesenterite retracticle sclerosante. Policlinico 31:
$575-581,1924$

3. Ogden WW, Nradburn DM, Rives JD. Paniculitis of the mesentery. Ann Surg 151: 659-668, 1960.

4. Daskalogiannaki M, Voloudaki A, Prassopoulos P, et al. CT evaluation of mesenteric panniculitis: prevalence and associated diseases. AJR Am J Roentgenol 174: 427-431, 2000.

5. Scudiere JR, Shi C, Hruban RH, et al. Sclerosing mesenteritis involving the pancreas: a mimicker of pancreatic cancer. Am J Surg Pathol 34: 447-453, 2010.

6. Chen TS, Montgomery EA. Are tumefactive lesions classified as sclerosing mesenteritis a subset of IgG4-related sclerosing disorders? J Clin Pathol 61: 1093-1097, 2008.

7. Salvarani C, Valli R, Boiardi L, et al. IgG4-associated sclerosing mesenteritis. Clin Exp Rheumatol 29: S79-S80, 2011.

8. Nomura Y, Naito Y, Eriguchi N, et al. A case of IgG4-related sclerosing mesenteritis. Pathol Res Pract 207: 518-521, 2011.

9. Minato H, Shimizu J, Arano Y, et al. IgG4-related sclerosing mesenteritis: a rare mesenteric disease of unknown etiology. Pathol Int 62: 281-286, 2012.

10. Mori E, Kamisawa T, Tabata T, et al. A case of IgG4-related mesenteritis. Clin J Gastroenterol 8: 400-405, 2015.

11. Avincsal MO, Otani K, Kanzawa M, et al. Sclerosing mesenteritis: A real manifestation or histological mimic of IgG4-related disease? Pathol Int 66: 158-163, 2016.

12. Lee SJ, Park CK, Yang WI, Kim SK. IgG4-related sclerosing mesenteritis. J Pathol Transl Med 50: 309-311, 2016.

13. Gomes DC, Quaresma L. Sclerosing mesenteritis: a benign cause of mesenteric mass lesions. Pan Afr Med J 27: 228, 2017.

14. Kitagawa S, Okamura K. IgG4-related sclerosing mesenteritis. Am J Gastroenterol 112: 834, 2017.

15. Greenbaum A, Yadak N, Perez S, Rajput A. Surgical management of isolated mesenteric autoimmune disease: addressing the spectrum of IgG4-related disease and sclerosing mesenteritis. BMJ Case Rep 2017: bcr2017220400, 2017.

16. Hasosah MY, Satti MB, Yousef YA, et al. IgG4-related sclerosing mesenteritis in a 7-year-old Saudi girl. Saudi J Gastroenterol 20: 385-388, 2014.

17. Michaud Maturana M, Panayotidis I, Psarelis S, et al. Elevated CA-125 in IgG4 mesenteritis: a red herring or a disease biomarker? Case report and literature review. Rheumatol Int 39: 1285-1289, 2019.

18. Butt Z, Alam SH, Semeniuk O, et al. A case of IgG4-related sclerosing mesenteritis. Cureus 10: e2147, 2018.

19. Kamisawa T, Zen Y, Pillai S, Stone JH. IgG4-related disease. Lancet 385: 1460-1471, 2015.

20. Deshpande V, Zen Y, Chan JK, et al. Consensus statement on the pathology of IgG4-related disease. Mod Pathol 25: 1181-1192, 2012.

21. Umehara H, Okazaki K, Masaki Y, et al. Comprehensive diagnostic criteria for IgG4-related disease (IgG4-RD), 2011. Mod Rheumatol 22: 21-30, 2012.

22. Zen Y, Onodera M, Inoue D, et al. Retroperitoneal fibrosis: a clinicopathologic study with respect to immunoglobulin G4. Am J Surg Pathol 33: 1833-1839, 2009.

23. Kamisawa T, Okamoto A. IgG4-related sclerosing disease. World J Gastroenterol 14: 3948-3955, 2008.

24. Strehl JD, Hartmann A, Agaimy A. Numerous IgG4-positive plasma cells are ubiquitous in diverse localised non-specific chronic inflammatory conditions and need to be distinguished from IgG4-related systemic disorders. J Clin Pathol 64: 237-243, 2011.

25. Sabaté JM, Torrubia S, Maideu J, et al. Sclerosing mesenteritis: imaging findings in 17 patients. AJR Am J Roentgenol 625-629, 1999.

26. Bae JH, Kim SH, Ahn SB, et al. A case of idiopathic sclerosing mesenteritis with retroperitoneal fibrosis. Korean J Gastroenterol 58: $221-225,2011$.

The Internal Medicine is an Open Access journal distributed under the Creative Commons Attribution-NonCommercial-NoDerivatives 4.0 International License. To view the details of this license, please visit (https://creativecommons.org/licenses/ by-nc-nd/4.0/).

(C) 2020 The Japanese Society of Internal Medicine Intern Med 59: 513-518, 2020 